\title{
Assessment of lipid and thyroid biomarkers in cattles infected with babesiosis in Lahore, Pakistan
}

\author{
Mariyum Hussain ${ }^{1}$, Hamida Ali $^{1 *}$, Nabila Roohi ${ }^{2}$ and Muhammad \\ $\mathrm{Naeem}^{3}$ \\ 1. Department of Zoology ,Sardar Bahadur Khan Women's University Quetta-Pakistan \\ 2. Department of Zoology, University of the Punjab, Lahore-54590-Pakistan \\ 3. Center for Advanced Studies in Vaccinology and Biotechnology (CASVAB), University of Balochistan, \\ Quetta-Pakistan \\ *Corresponding author's email: hamida.sbkwu@gmail.com \\ Citation \\ Mariyum Hussain, Hamida Ali, Nabila Roohi and Muhammad Naeem. Assessment of lipid and thyroid \\ biomarkers in cattles infected with babesiosis in Lahore, Pakistan. Pure and Applied Biology. Vol. 10, Issue 1, \\ pp311-317. http://dx.doi.org/10.19045/bspab.2021.100033
}

\begin{tabular}{llll}
\hline Received: 16/06/2020 & Revised: 24/08/2020 & Accepted: 04/09/2020 & Online First: 21/09/2020 \\
\hline \hline
\end{tabular}

\section{Abstract}

Babesiosis is a tick-borne disease found in cattles, transmitted by piroplasm which enters into the host RBCs and destroys them completely. It also affects different organs resulting into the death of animals. This study was aimed to evaluate the biochemical and hormonal outcomes of babesiosis in cattles in Lahore, Pakistan. Blood samples were collected from 89 cows from military farm of Lahore and brought to physiology/endocrinology laboratory, University of Punjab for biochemical analysis. Different parameters such as glucose, cholesterol, high density lipoprotein (HDL) and triglycerides (TG) were analyzed by chemistry analyzer while thyroxine (T4) was determined by enzyme-linked immunosorbent assay (ELISA). Statistical analysis was carried out using independent samples t-test. Out of 89 cattles, $25 \%(n=22)$ were found to be infected with Babesia. Results of present investigation demonstrated prominent increase in levels of glucose $(P<0.001)(41 \%)$ and triglycerides $(P<0.001)(22 \%)$ in infected cattles. Whereas, significant decrease was evidenced in concentration of thyroxine $(P<0.01)$ $(21 \%)$ and HDL $(P<0.001)(30 \%)$ in Babesia-infected cattles as compared to non-infected cattles. However, levels of cholesterol demonstrated non-significant decrease $(15 \%)$ in Babesia-infected animals than healthy animals. Such variations in thyroid and lipid profile can increase the risk of hyperglycemia, hepatic and cardiac dysfunction among cattles.

Keywords: Babesia; Cattles; ELISA; High density lipoprotein; Thyroxine; Triglycerides Introduction

Babesiosis is a tick-borne hemoprotozoan disease with host-specific features carried by members of the Babesia genus. Babesiosis affects cattle, horses, sheep, goats, pigs, dogs and wild animals. Life cycle of Babesia within the tick body comprises of three stages i.e. gamogony, sporogony and merogony. Babesia bovis, Babesia bigemina and Babesia divergens are the parasites which are responsible for babesiosis in cattles. However, cattles are affected more by B. bovis and B. bigemina. Rhipicephalus microplus and Rhipicephalus annulatus are the ticks which are responsible for the transmission of $B$. bovis and B. bigemina among cattles [1].

The location of B. bovis is in the center of erythrocyte and is considered as a small 
parasite. It measures about 0.5-1.0 $\mu \mathrm{m}$ wide and 1-1.5 $\mu \mathrm{m}$ long. While, $B$. bigemina is pear-shaped, large parasite which is about 1-1.5 $\mu \mathrm{m}$ wide and 3-3.5 $\mu \mathrm{m}$ long and with a two different redstaining dots $(B$. bovis and $B$. divergens have one only) [1].

The acute disease generally runs a course of one week. The first sign is fever, which persists throughout the course of disease, and is accompanied with inappetence, increased respiratory rate, muscle tremors, anemia, jaundice, weight loss, hemoglobinemia and hemoglobinuria in the final stages. Cattles infected with babesiosis have reduced fertility, increased fatality rates and heightened risk of producing spoilt milk. Adult female ticks also cause problems in cattles in gaining weight [2].

Infected animals should be treated with anti-parasitic drugs. The proper administration and efficacy of drug can lead to the successful treatment only if the disease is diagnosed earlier [3]. The infection is prevalent in tropical and subtropical areas. Babesiosis is more common in the wet season when the tick vectors are abundant, but less common in dry weather or dry areas where the survival of ticks is limited [1].

Glucose is produced by the liver through the process of glycogenolysis and gluconeogenesis [4]. An elevated level of glucose in the blood predisposes individuals to certain metabolic diseases.

The liver failure in cattles infected with Theileria and Babesia species is due to decreased levels of globulin and albumin which causes a decrease in the total protein [5]. Due to decrease in the albumin synthesis and increase in the albumin catabolism, the previous studies showed that theileriosis and babesiosis have a damaging impact on hepatocytes which thus causes complication in the hepatic function [6]. Liver produces cholesterol which is important for the body function. Excess cholesterol will increase the risk of a heart diseases in cattles [7]. High density lipoprotein (HDL) and low density lipoprotein (LDL) are the two main types of cholesterol $[7,8]$.

Thyroid, an endocrine gland produces two hormones: T4 (tetraiodothyronine/thyroxine) and T3 (triiodothyronine). These hormones regulate the different processes of metabolism [911]. T4 formed by the thyroid gland is carried to the tissues for modification by different binding proteins. T4 through different courses of de-iodinases is converted to T3 [12].

The present study was aimed to determine the alterations in thyroxine hormone, glucose level and lipid profile (cholesterol, HDL and TG) in cattles due to babesiosis.

\section{Materials and Methods Sample collection}

A total of 89 blood samples were collected from cows from military dairy farm in Lahore, Punjab and were brought to physiology/endocrinology laboratory, Department of Zoology, University of the Punjab, for further biochemical and hormonal analyses.

\section{Microscopic examination of Babesia}

The blood sample of each animal was smeared on glass slide for microscopic examination. Prior to examination, smeared slides were air-dried quickly and fixed with methyl alcohol for one minute. After fixation each slide was again airdried and stained with Giemsa solution for 30-40 minutes. After staining, slides were allowed to dry and washed with distilled water so that any residue left could be washed away. The stained slides were examined under the microscope using immersion oil.

\section{Biochemical analysis of blood samples}

Blood samples collected in vacutainers were centrifuged for 5 minutes and serum was separated from the samples and then stored at $-80^{\circ} \mathrm{C}$ for the biochemical and hormonal analyses. Blood glucose, cholesterol, HDL and triglycerides were analyzed by commercially available kits using clinical chemistry analyzer. 
However, thyroxine was analyzed by ELISA.

\section{Statistical analysis}

Data was analyzed using Graph Pad Prism (USA) software. Independent samples ttest was applied to find out significant differences in the different biochemical and hormonal parameters between the Babesia-infected cattles and the noninfected ones.

\section{Ethics statement}

The study was approved by the institutional review committee of University of Punjab, Lahore, Pakistan.

\section{Results}

Overall 25\% (22/89) cattles were found to be infected with babesiosis. Table 1 shows the means of different biochemical and hormonal parameters in infected and healthy cattles. The mean glucose level was $48.22 \pm 2.80 \mathrm{mg} / \mathrm{dL}$ in healthy cattles and $67.96 \pm 3.26 \mathrm{mg} / \mathrm{dL}$ in infected cattles. Marked increase of $41 \%(P<$ $0.001)$ in the glucose level was detected in infected group as compared to healthy group of cows (Fig. 1a). Moreover, the mean T4 values of healthy and infected animals were $200.3 \pm 8.55 \mathrm{ng} / \mathrm{mL}$ and $158.6 \pm 16.14 \mathrm{ng} / \mathrm{mL}$, respectively. A significant decrease of $21 \%(P<0.05)$ in the T4 level was observed in infected group as compared to healthy group of cows (Fig. 1b).

The mean cholesterol levels of healthy and infected animals were $106.7 \pm 6.01 \mathrm{mg} / \mathrm{dL}$ and $92.32 \pm 5.09 \mathrm{mg} / \mathrm{dL}$, respectively. Cholesterol level demonstrated slight decrease of $15 \%$, in infected group as compared to healthy group of cows (Fig. 1c). Moreover, the mean HDL values of healthy and infected animals were $62.74 \pm$ $2.66 \mathrm{mg} / \mathrm{dL}$ and $44.08 \pm 3.70 \mathrm{mg} / \mathrm{dL}$, respectively. A prominent decrease of $30 \%$ $(P<0.001)$ in HDL was evidenced in infected group as compared to healthy cows (Fig. 1d). The mean triglycerides values of healthy and infected animals were $40.42 \pm 0.73 \mathrm{mg} / \mathrm{dL}$ and $49.28 \pm 2.67$ $\mathrm{mg} / \mathrm{dL}$, respectively. A significant increase of $22 \%(\mathrm{P}<0.001)$ in triglycerides, was detected in infected group as compared to healthy group of cows (Fig. 1e).

\section{Discussion}

Babesiosis additionally alluded to as piroplasmosis, tick fever, red water or texas fever is a risky, obtrusive, febrile and tick-borne disease $[13,14]$. The protozoan Babesia includes B. bovis, B. bigemina, $B$. major and $B$. divergens. Among these species B.bovis and B. bigemina are the most crucial species that cause babesiosis in cows worldwide [15, 16]. Ticks belonging to species of Ixodid, Rhipicephalus, Haemaphysalis and Dermacentor affect cows in Pakistan [17]. According to Pakistan Economic Survey (2013-2014), it is estimated that the population of cows are from 36 to 41 millions in Pakistan. Cows are the main source of milk giving 19,000 to 32,000 million tons milk every day. The economy of Pakistan thus depends upon its livestock.

Table 1. A comprehensive presentation of biochemical and hormonal parameters in Babesia-infected and healthy cattles

\begin{tabular}{|c|c|c|c|c|}
\hline Parameters & Healthy Cattles & Infected Cattles & $\boldsymbol{P}$-value & $\boldsymbol{\%} \uparrow \mathbf{\text { }} \downarrow$ \\
\hline Glucose $(\mathrm{mg} / \mathrm{dL})$ & $48.22 \pm 2.80$ & $67.96 \pm 3.26$ & $0.0001^{* * *}$ & $41 \% \uparrow$ \\
\hline Thyroxine (T4) (ng/mL) & $200.3 \pm 8.55$ & $158.6 \pm 16.14$ & $0.0160 *$ & $21 \% \downarrow$ \\
\hline Cholesterol (mg/dL) & $106.7 \pm 6.01$ & $92.32 \pm 5.09$ & 0.1610 & $15 \% \downarrow$ \\
\hline HDL (mg/dL) & $62.74 \pm 2.66$ & $44.08 \pm 3.70$ & $0.0002 * * *$ & $30 \% \downarrow$ \\
\hline Triglycerides (mg/dL) & $40.42 \pm 0.76$ & $49.28 \pm 2.67$ & $<0.0001 * * *$ & $22 \% \uparrow$ \\
\hline
\end{tabular}

Values are mean \pm SEM, $\uparrow$ or $\downarrow$ indicates increase or decrease, respectively

$*$ and $* * *$ indicates significance at $\mathrm{P}<0.05$ and $\mathrm{P}<0.001$, respectively 

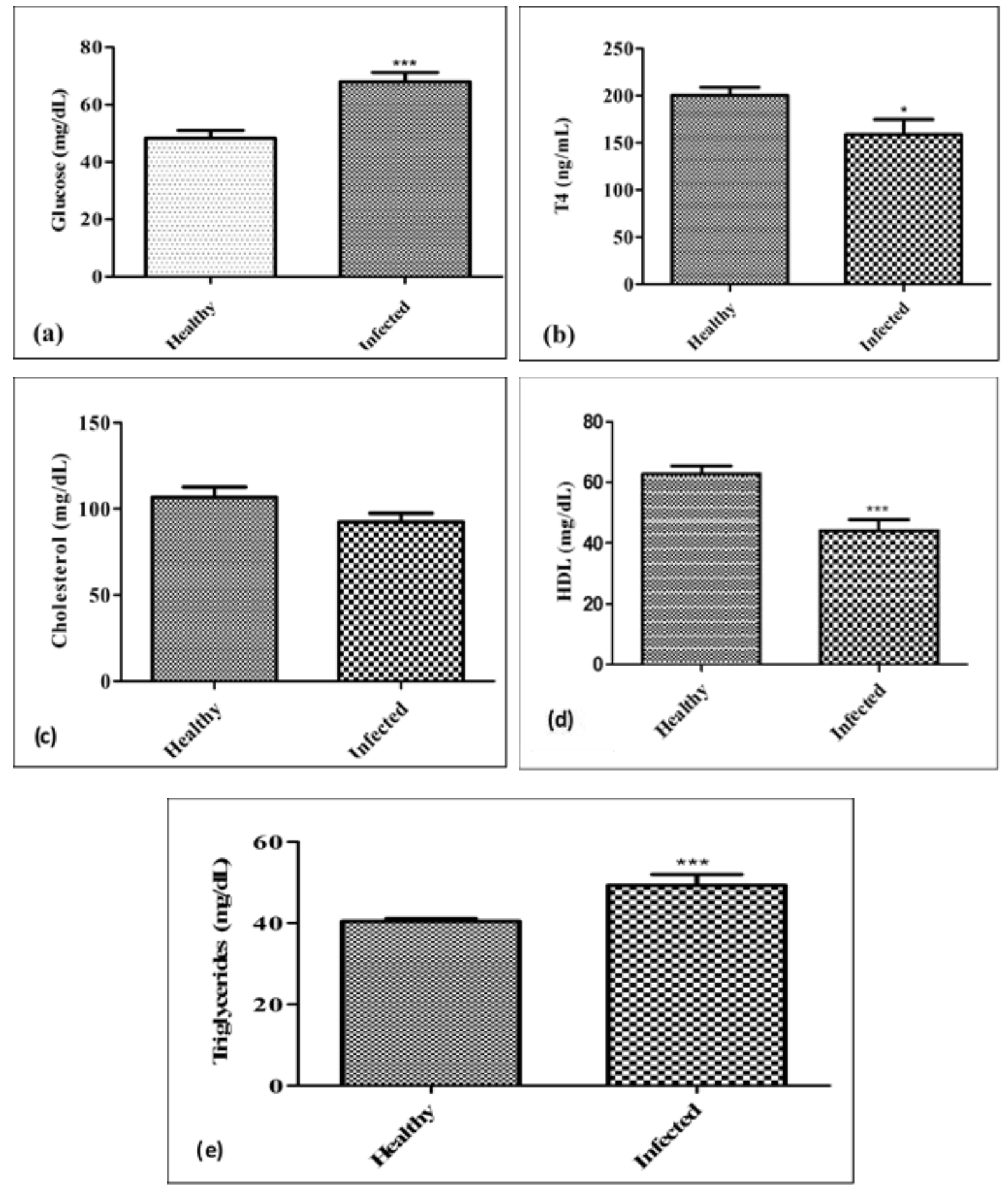

Figure1(a-e). Graphical representation of different biochemical and hormonal parameters in Babesia-infected and healthy cattles. (Values are Mean \pm SEM, Significant at $* \mathrm{P} \leq \mathbf{0 . 0 5}$ and $* * * \mathrm{P} \leq \mathbf{0 . 0 0 1})$

Overall the prevalence of babesiosis was recorded to be $25 \%$ among cows in this investigation. Different parameters like glucose, thyroxine, cholesterol, HDL and triglycerides were determined. Cattles infected with Babesia parasites showed significant increase in the level of glucose i.e $41 \%$. The findings of this investigation were supported by [18-21]. It is well known that increase in gluconeogenesis 
causes increase in the level of blood glucose [22].

Significant decrease in the thyroxine concentration has been observed in our study. The secretory product of thyroid gland is thyroxine hormone (T4) [23]. The presence of thyroxine in animal's blood is the indicator of iodine availability [24]. Decrease in the T4 concentration is due to deiodination of $\mathrm{T} 4$ to $\mathrm{T} 3$, a more active form which results due to high metabolic load [23].

In our study significant decrease in the serum cholesterol has been observed. Similar finding has also been reported by [25]. According to [26] diarrhea and anorexia may be one the reason for decreased level of cholesterol. We found a significant decrease in HDL level. [27] also reported reduction in the concentration of HDL. Decrease in HDL level may be due to decreased level of cholesterol [28]. Increase in the hepatic production of triglycerides or abnormality in the removal of triglycerides from circulation causes an increase in the level of triglycerides. Moreover, in acute phase the increased triglyceride level are thought to be associated with host response [29].

Blood chemistry is changed in different conditions, for example, extraordinary irresistible ailments, liver problems, tissue injury, and numerous other physiological issues. Hence, biochemical analyses of blood serum are very useful to get insight into the metabolic and health status of animals. Biochemical determination of serum constituents can provide important information as relating to age, sex, nutrition, and physiological status of the animal [30]. Early prediction of potential health risks associated with babesiosis will be helpful in improving the health of these animals by timely treatment and management. Timely and accurate treatment measures will no doubt improve the outcomes of treatment thus increasing the survival rate.

\section{Conclusion}

In conclusion, the results of present study suggested that cows infected with babesiosis are facing stress situation and are at increased risk of hyperglycemia and consequent diabetes as indicated by high blood glucose. Further, raised levels of triglycerides but decreased HDL indicated that these cows were also at increased risk of hepatic and cardiac dysfunction.

\section{Authors' contributions}

Conceived and designed the experiments: N Roohi, Performed the experiments: $M$ Hussain, Analyzed the data: H Ali \& M Naeem, Contributed reagents/ materials/ analysis tools: $\mathrm{M}$ Naeem \& N Roohi, Wrote the paper: M Hussain \& H Ali.

\section{Acknowledgements}

The authors wish to thank Lt.Col Mohammad Hasan for his continuous support and help throughout their research.

\section{References}

1. OIE (2012) Manual of Diagnostic Tests and Vaccines for Terrestrial Animals. Bovine Babesiosis. Paris. pp. 1-15.

2. Blumenthal UJ, Fleisher JM, Esrey SA \& Peasey A (2001). Epidemiology: a tool for the assessment of risk. IWA Publishing. pp.136-158.

3. de Vos AJ, De Waal DT \& Jackson LA (2004). Bovine babesiosis. In: Coetzer JAW, Tustin RC, editors. Infectious diseases of livestock. Oxford University Press, Capetown. 406-424.

4. Mitrakou A (2011). Kidney: its impact on glucose homeostasis and hormonal regulation. Diabetes Res Clin Pract 93(S1): S66-S72.

5. Apaydin B \& Dede S (2010). Electrophoretic profile of serum protein fractions from sheep naturally infected with Babesia ovis. Revue de Medecine Veterinaire 161(2): 57-60.

6. Hussein AH, Mohammed NAES \& Mohammed HK (2007). Theileriosis and babesiosis in cattle: haemogram and some biochemical parameters. In 
Proceedings of XIII International Congress of International Society of Animal Hygiene, Tartu, Estonia. pp. 143- 150.

7. Kurain J \& Perumal J (2013). Nature's Remedies Made Simple. Bangkok, Thailand: Sirivatana Interprint Public Company Limited. pp. 9-11.

8. Aryati N (2004). Pengaruh Konsumsi Serat dan Antioksidan (Vitamin A, C dan E) terhadap Kejadian Penyakit Jantung Koroner (Studi Pasien Rawat Jalan di BPRSUD Salatiga). Diss Diponegoro University.

9. Oetting A \& Yen PM (2007). New insights into thyroid hormone action. Best Pract Res Clin Endocrinol Metab 21(2): 193-208.

10. Cheng SY, Leonard JL \& Davis PJ (2010). Molecular aspects of thyroid hormone actions. Endocr Rev 31(2): 139-170.

11. Brent GA (2012). Mechanisms of thyroid hormone action. J Clin Invest 122(9): 3035-3043.

12. Williams GR (2008). Neurodevelopmental and neurophysiological actions of thyroid hormone.J Neuroendocrinol 20(6): 784-794.

13. Gohil S, Herrmann S, Günther S \& Cooke BM (2012). Bovine babesiosis in the 21st century: advances in biology and functional genomics. Int $\mathbf{J}$ Parasitol 43(2): 125-132.

14. Mahmud MA, Belal S \& Hossain MA (2015). Prevalence of theileriosis and babesiosis in cattle in Sirajganj district of Bangladesh. Res Agric Livest Fish 2(1): 79- 86.

15. da Silva JB, André MR, da Fonseca $\mathrm{AH}$, de Albuquerque Lopes CT, da Silva Lima DH, de Andrade SJ, Oliveira CM \& Barbosa JD (2013). Molecular and serological prevalence of Babesia bovis and Babesia bigemina in water buffaloes in the north region of Brazil. Vet Parasitol 197(3-4): 678-681.
16. Bock R, Jackson L, de Vos A \& Jorgensen W (2004). Babesiosis of cattle. Parasitol 129(S1): S247-S269.

17. Durrani AZ, Shakoori AR \& Kamal N (2008). Bionomics of Hyalomma ticks in three districts of Punjab, Pakistan. $J$ Anim Plant Sci 18(1): 17-23.

18. Zulfiqar S, Shahnawaz S, Ali M, Bhutta AM, Iqbal S, Hayat S, Qadir S, Latif M, Kiran N, Saeed A, Ali M \& Iqbal F (2012). Detection of Babesia bovis in blood samples and its effect on the hematological and serum biochemical profile in large ruminants from Southern Punjab. Asian Pac J Trop Biomed 2(2): 104-108.

19. Schoeman JP \& Herrtage ME (2007). The response of the pituitary-adrenal and pituitary-thyroidal axes to the plasma glucose perturbations in Babesia canis rossi babesiosis. J S Afr Vet Assoc 78(4): 215-220.

20. Stockham SL, Kjemtrup AM, Conrad PA, Schmidt DA, Scott MA, Robinson TW, Tyler JW, Johnson GC, Carson CA \& Cuddihee P (2000). Theileriosis in a Missouri beef herd caused by Theileria buffeli: case report, herd investigation, ultrastructure, phylogenetic analysis, and experimental transmission. Vet Pathol 37(1): 11-21.

21. Yeruham I, Avidar Y, Aroch I \& Hadani A (2003). Intra-uterine Infection with Babesia bovis in a 2day-old Calf. $J$ Vet Med B 50(2): 6062.

22. Huntington GB \& Archibeque SL (2000). Practical aspects of urea and ammonia metabolism in ruminants. $J$ Anim Sci 77(E-Suppl): 1-11.

23. Todini L (2007). Thyroid hormones in small ruminants: effects of endogenous, environmental and nutritional factors. Animal 1(7): 9971008.

24. Paulíková I, Seidel H, Nagy O, Tóthová C \& Kováč G (2011). Concentrations of thyroid hormones in various age categories of ruminants 
and swine. Acta veterinaria 61(5-6): 489-503.

25. Singh R, Barden A, Mori $\mathrm{T} \&$ Beilin L (2001). Advanced glycation endproducts:

\section{a} review. Diabetologia 44(2): 129-146.

26. Col R \& Uslu U (2007). Changes in selected serum components in cattle naturally infected with Theileria annulata. Bull Vet Inst Pulawy 51(1): 15-18.

27. Cunha TS, Moura MJ, Bernardes CF, Tanno AP \& Marcondes FK (2005). Vascular sensitivity to phenylephrine in rats submitted to anaerobic training and nandrolone treatment. Hypertension 46(4): 1010-1015.
28. Nakamura Y, Gojobori T \& Ikemura $\mathrm{T}$ (2000). Codon usage tabulated from international DNA sequence databases: status for the year 2000. Nucleic Acids Res 28(1): 292.

29. Carpentier YA \& Scruel O (2002). Changes in the concentration and composition of plasma lipoproteins during the acute phase response. Curr Opin Clin Nutr Metab Care 5(2): 153158.

30. Osman TEA \& Al-Busadah KA (2003). Normal concentrations of twenty serum biochemical parameters of she-camels, cows and ewes in Saudi Arabia. Pak J Biol Sci 6(14): 12531256. 